\title{
No conclusion on low level lead hazards
}

A government report, published last week, has provoked strong criticism from the lobby demanding reductions in the amount of lead added to petrol. The report, Lead and Health*, concludes that lead in air is not the most significant contributor to lead contamination in people: food and water are more important. "In the vast majority of the population", it says, "airborne lead, including that derived from petrol, is usually a minor contributor to the body burden".

The working party on lead, set up in November 1979 under the Chairmanship of Professor P.J. Lawther, head of the MRC Toxicology Unit at St Bartholomew's Hospital, to prepare the report, concludes that it has only been able to satisfy one of the objectives required by its terms of reference - that of assessing the role of lead from petrol in relation to the other sources of lead in the environment. Its other aims - "to review the overall effects on health of environmental lead from all sources and, in particular, its effects on the health and development of children" - have been more difficult to achieve.

The toxicity of heavy exposure to lead is well known. The main controversy is over whether or not exposure to fairly low levels can effect health, especially the mental health of children. Several studies, in the US and Europe, suggest that children exposed to levels of lead which would not be high enough to result in the conventional signs of lead poisoning, have lower IQs and more behavioural problems than children who have not been exposed, or only very slightly.

The working party tried to meet the second part of its terms of reference by reviewing these studies. It concludes that there is no evidence of "deleterious effects at blood lead levels below about $35 \mu \mathrm{g} / \mathrm{dl}$; neither is there any doubt about the serious consequence of blood lead levels above about $80 \mu \mathrm{g} / \mathrm{dl}$; at intermediate concentrations, however, it says that the evidence is still very uncertain.

Many of the studies on the intelligence and behaviour of children are criticised in the report for not giving full details of their methodology. It says that in many of them, conflicting results have meant that the working party has not been able to come to any "clear conclusions concerning the effects of small amounts of lead on the intelligence, behaviour and performance of children". It recommends that further and more careful studies should be done: in particular better tests for examining intellectual function and behaviour in small groups of children are needed as is more research on the effects of pre-natal exposure on subsequent development.

Nevertheless, the report recommends

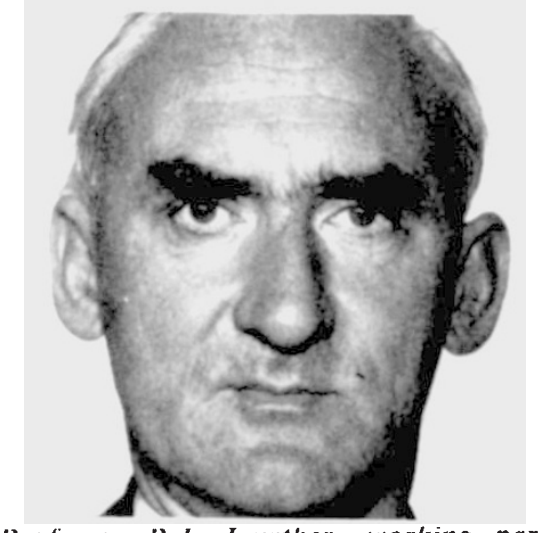

of the hazard.

Other recommendations made by the report are the elimination of lead from manufactured foods - this is particularly a problem with canned foods - the development of guidelines for acceptable concentrations of lead in soil - more research also needs to be done on how plants take up lead from soil - and better education of the public on the hazards of lead especially to small children.

On the controversial topic of emissions of lead to the air from traffic, the report recommends that it should be progressively reduced and that the annual mean concentration of lead in air should be kept at less than $2 \mu \mathrm{g} / \mathrm{m}^{3}$ in places where people spend a lot of time. Measures to achieve these limits may include "reduction of emissions, the relocation of industry or housing or traffic management schemes".

The report hs been criticized by the antilead lobby. Parents Against Lead issued a statement at the time of the report's release saying that it had not taken into account evidence linking birth defects with lead contamination of the mother neither had it considered research already done showing that much of the lead in food comes from the air. To suggestions that the working party had been swayed by the oil industry, Professor Lawther said that each member of the party had their own scientific reputation to maintain and they had struggled to produce a fair scientific assessment of the subject.

Judy Redfearn in tap water in badly affected areas. The import and use of lead containing cosmetics should be discouraged, it says, and potential users should be made aware Working Party on lead in the Environment
Lead and Health: the report of a DHSS HMSO $£ 4.50$

\section{Dual support system for review}

THE 'dual support' system whereby UK universities pay for buildings, services, technicians, basic laboratory equipment and salaries while research councils pay short-term grants for specific research is to be questioned by a new 7-man working party which will report ultimately to the Department of Education and Science.

The working party is "to review the current arrangements for the support of university research in the natural and social sciences". It is drawn from the Advisory Board for the Research Councils, which advises government on the allocation of the science budget among the research councils, and the University Grants Committee which provides universities with their basic running funds. The party will be chaired by Sir Alec Merrison, Chairman of the ABRC; other members include Dr Edward Parkes, Chairman of the UGC, and Sir Geoffrey Allen, Chairman of the Science Research Council (largest of the five research councils).
The feeling has been growing among the research councils that cut-backs in the UGC grant have fallen disproportionately on science, engineering, and medicine which through their laboratories have greater service requirements than the humanities. Applications to the research councils are increasingly including requests for equipment which would normally have been purchased through the university, and demands are increasing on research council central facilities (such as computers).

The working party will collect evidence, Sir Alec told Nature last week "and we can't rely on just a few scraps of information". On the other hand, the problem was too urgent to wait for the drafting and processing of a large questionnaire. The party "will not look at the total level of academic manpower" but will consider the problem of post-doctoral fellows and the provision of technicians.

"There is broad agreement that something is going wrong" with dual support 